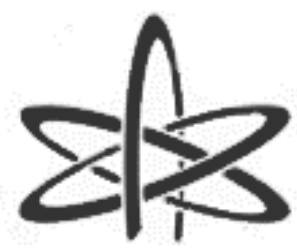

BJRS
BRAZILIAN JOURNAL

$\mathrm{OF}$

RADIATION SCIENCES

05-02 (2017) 01-17

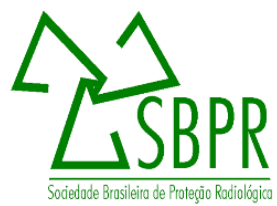

\title{
Compliance and quality control monitoring of diagnostic X-ray facilities in Dar es Salaam city,
}

\section{Tanzania}

\author{
Leonid L. Nkuba ${ }^{{ }^{*}}$ and Pendo B. Nyanda ${ }^{\mathbf{1}}$ \\ ${ }^{1}$ Tanzania Atomic Energy Commission, Radiation Control Directorate. \\ P.O Box 80479 Dar es Salaam zonal office, Dar es Salaam, Tanzania \\ *Corresponding author email: leonid.nkuba@taec.or.tz
}

\begin{abstract}
The compliance evaluation and quality control measurements on 60 diagnostic $X$-ray units were performed. The results on legal compliance show that $25 \%$ of X-ray facilities operated without or with an expired license. The rest of the centers were new and had already applied for license and others had valid licenses. For basic requirements compliance, $47 \%$ of $\mathrm{X}$-ray facilities did not have the changing cubicles, $37 \%$ of $\mathrm{X}$-ray facilities did not post radiation warning sign and symbols also $46 \%$ of units were found either without protective gear or operated by unqualified personnel. The QC test results showed that $93 \%$ had X-ray tube voltage within the tolerance limit of $10 \%$ and $\mathrm{HVL} \geq 2.3 \mathrm{mmAl}$, at $80 \mathrm{kV}$ was observed in $98.2 \%$ of the units, whereas $98 \%$ of exposure had acceptable $\mathrm{kV}$ reproducibility within the tolerance limit of $5 \%$. Of the $\mathrm{X}$-ray generators assessed, $93 \%$ had tolerable mAs linearity. $93 \%$ and $97 \%$ had acceptable beam alignment and light beam diaphragm. Of the assessed units, $13(93 \%)$ had tube leakage $<1000 \mu \mathrm{Gy} / \mathrm{hr}$ at $1 \mathrm{~m}$. For shielding tests, $47 \%$ of units had radiation levels above $0.5 \mu \mathrm{Sv} / \mathrm{hr}$ at the main door leading to the $\mathrm{X}$-ray rooms and the registration area. The dose rates $>10 \mu \mathrm{Sv} / \mathrm{hr}$ were recorded at viewing windows, walls and doors of control cubicles and behind the doors of changing cubicles. These dose rates indicating higher health risk to workers and member of public.
\end{abstract}

Key Words: Legal, Basic requirements Compliance, Quality Control and X-ray Unit 


\section{INTRODUCTION}

Since the discovery of X-rays in 1895, the diagnosis through the use of X-ray equipment is one of the most important fields in clinical medicine. The widespread use of X-ray in the diagnosis and management of patients has led to increased radiation exposure. Diagnosis radiology is being refereed as the main contributor to the man-made exposure of general population [1]. Since quality assurance (QA) programmes ensure high quality diagnostic images with the least possible radiation dose to the patient, all countries have been recommended to introduce programmes for their radiological facilities [2]. Quality-control programs in diagnostic radiology aim to ensure the optimal performance of all imaging components. These programs lead to the production of images with the highest quality and the lowest possible radiation dose to patients, operators and members of public, while maintaining a high diagnostic value to patients. The goal of quality-control programs is to help reduce costs through eliminating unproductive imaging, caused by the inefficiency of devices or materials, which may occur in a complex chain leading to the finished product $[3,4]$.

In Tanzania, the powers related to registration, documentation, authorization, insurance of compliance and quality control programmes of ionization practices have been vested to Tanzania Atomic Energy Commission (TAEC) by the law [5]. The owners of the X-ray facilities are required by the law to acquire a License from a regulatory body (TAEC) before rendering X-ray services [5, 6] also the operator of the X-ray machine is required by the TAEC to have expertise in the area, a Diploma in Diagnostic Radiology (DDR) is a minimum qualification required [5]. According to Ministry of health records, as of March 2017, Tanzania is having a total of 580 registered radiographers, 460 are full registered, and 120 are having provisional registration [6]. Excluding 12 new centres which were not rendering X-ray services, the remaining $48 \mathrm{X}$-ray facilities reported on the number of patients examined per day. The dispensaries reported to examine 3 - 5 patients a day, the health centres reported to examine $7-15$ patients per day, whilst hospitals reported to examine $20-70$ patients per day. In all the survey health facilities, the total number of examined patients per day was 790. An extrapolation can be done to have the total number of patients examined per year. 
As the quality control programme of all X-ray equipment in use is required by legislation $[5,8]$. In this paper, compliance and quality control of the X-ray facilities were the focus. For compliance monitoring, legal compliance and basic requirements on the design and layout of X-ray rooms were evaluated. And for quality control, monitoring of radiation leakage, total beam filtration, exposure time, tube voltage $(\mathrm{kVp})$, radiation output and accuracy of beam were measured. Where available the national standards and international tolerance limits established by FDA, NCRP, AAPM, ICRP and ACR were used as a reference [9, 10]. Therefore, the aim of this study was to assess the compliance and quality control monitoring of X-ray facilities in Dar es Salaam City to detect changes in tube voltage and exposure time as conventional X-ray exposure parameters.

\section{MATERIALS AND METHODS}

\subsection{Diagnostic X-ray Units}

As shown in Table 1, for general radiography, Tanzania is having 506 registered X-ray machines, while Dar es Salaam City is having 178 registered X-ray machines [11]. These 178 diagnostic X-ray units represent about $35 \%$ of the total diagnostic X-ray units of the Country. Also according to the 2012 National Census, Dar es Salaam region had a population of 4,364,541 [12]. This is $9.1 \%$ of the total population of the Country. The city is the most densely populated region in the Country with 3,133 people per square kilometer. These features make the city of Dar es Salaam very important and it's the reason why it was selected for this study.

In the present study, the performance characteristics and basic requirements on the design and layout of 60 diagnostic X-ray units were carried out during 2016 - 2017. These 60 diagnostic X-rays units were from both government and private hospitals. They represent about $34 \%$ of the total diagnostic X-ray units of the Dar es salaam City and $12 \%$ of diagnostic X-rays units in the Country (Table 1). The tested units were conventional diagnostic medical X-rays only. All hospitals were located in Dar es salaam City, Tanzania. Overall, the X-ray units evaluated in this study comprises of 19 Seamen, 16 Phillips, 7 Allengers, 4 Toshiba, while Shimadzu, Scanmobile and DK (Dong Kang) each had 2 units (making a total of 6 X-ray units), Pollux, Stephan, XGY GDX, Hofman, 
Hyun Dai, Villa, XG920 2A-Shanghai and Mediotronic had 1 unit each (making a total of 8 X-ray units).

Table 1: Diagnostic Radiology Equipment in the United Republic of Tanzania as Per 2016 [11].

\begin{tabular}{|c|c|c|c|c|}
\hline \multirow[b]{2}{*}{ REGION } & \multicolumn{4}{|c|}{ MODALITY } \\
\hline & $\begin{array}{c}\text { General } \\
\text { Radiography }\end{array}$ & $\begin{array}{l}\text { Fluoro- } \\
\text { Scopy }\end{array}$ & $\begin{array}{l}\text { Mammo- } \\
\text { graphy }\end{array}$ & $\begin{array}{c}\text { Computer } \\
\text { Tomography }\end{array}$ \\
\hline \multicolumn{5}{|l|}{ Tanzania Mainland } \\
\hline 1. Arusha & 22 & 1 & 1 & 3 \\
\hline 2. Dar es Salaam & 178 & 10 & 9 & 10 \\
\hline 3. Dodoma & 9 & 1 & 1 & \\
\hline 4. Geita & 2 & & & \\
\hline 5. Iringa & 18 & 1 & & \\
\hline 6. Kagera & 15 & 1 & & \\
\hline 7. Katavi & 3 & & & \\
\hline 8. Kigoma & 7 & 1 & & \\
\hline 9. Kilimanjaro & 37 & 3 & 1 & 1 \\
\hline 10. Lindi & 15 & 2 & & \\
\hline 11. Manyara & 11 & 2 & & 1 \\
\hline 12. Mara & 6 & 1 & & \\
\hline 13. Mbeya & 22 & 2 & 1 & \\
\hline 14. Morogoro & 21 & 2 & & \\
\hline 15. Mtwara & 12 & 2 & & \\
\hline 16. Mwanza & 27 & 2 & 1 & 3 \\
\hline 17. Njombe & 8 & 1 & & 1 \\
\hline 18. Pwani & 11 & 1 & & \\
\hline 19. Rukwa & 3 & 1 & & \\
\hline 20. Ruvuma & 11 & 1 & & \\
\hline 21. Shinyanga & 12 & 1 & & \\
\hline 22. Simiyu & 3 & & & \\
\hline 23. Singida & 12 & 1 & & \\
\hline 24. Tabora & 12 & 1 & & \\
\hline 25. Tanga & 16 & 1 & & \\
\hline \multicolumn{5}{|l|}{ Tanzania Zanzibar } \\
\hline 26. Kaskazini Pemba & 3 & & & \\
\hline 27. Kaskazini Unguja & 1 & & & \\
\hline 28. Kusini Pemba & 2 & & & \\
\hline 29. Kusini Unguja & 1 & & & \\
\hline 30. Mjini Magharibi & 6 & 1 & & \\
\hline TOTAL & 506 & 40 & 14 & 19 \\
\hline
\end{tabular}




\subsection{Basic Compliance and their assessments criteria}

The compliance evaluation focused on legal and standard compliance (design and layout). Legal compliance forms its bases on the atomic energy act No. 7 of 2003 . Whereby, every individual practicing ionization radiation is required to have the license of possess and use each year [5]. For Standard compliance, the ionizing radiation regulation gives clearly the basic requirements on the design and layout of X-ray rooms and the qualification of the operators.

The legal requirements information was collected via information in Table 2. The information gathered were the presence of the license for possess and use in a particular year, legal actions taken for non-compliance (e.g. fine and closing of the facility) [5]. Basic requirements of the X-ray facility (design and layout) were collected via information given in Table 2 [13]. According to IAEA, WHO and TAEC standards, the X-ray room should be at least 16 square meters ( $4 \mathrm{~m}$ by 4 $\mathrm{m})$ or as per machine manufacture's specifications. There should be sufficient space for a permanently built cubicle control.

The access doors should be of the sliding type giving better radiation protection. The overlap should be $100 \mathrm{~mm}$ each side. The doors should be lined with lead sheet of $2 \mathrm{~mm}$ thick or made of iron sheet $4 \mathrm{~mm}$ thick. The walls should be of concrete blocks $30 \mathrm{~cm}$ thick. The other requirements on the cubicle control, dark room (for facility which do not utilizes the computerized radiography system), window and air conditioners as well as the radiation warning notice, lights and symbols are well described in several documents [13] also given in Table 3. These criteria were used to evaluate the facilities design and layout.

\subsection{Exposure Parameters and Testing tools}

The performance measurements were focused on tube voltage $(\mathrm{kV})$, beam quality (HVL), exposure time (mAs), radiation output (tube leakage), beam alignment and accuracy of beam limiting device. And finally the shielding effectiveness was tested. Kilovoltage $(\mathrm{kV})$ reproducibility, it's an ability of radiographic unit to produce the same exposure even though in the short intervals, $\mathrm{kV}$ accuracy sets the level of reliability of X-ray equipment examined, this test establishes the difference between selected and measured $\mathrm{kV}$. For beam quality (HVL), HVL is that amount of absorbing 
material that will reduce the intensity of the primary beam to one-half its original value. The test is necessary as it shows how the low energy photons are removed from the X-ray beam. The ability of radiographic unit to produce a constant radiation output for various combinations of $\mathrm{mA}$ and exposure time is called mAs linearity. This test also attempts to establish if the same film density is achieved using the same $\mathrm{kVp}$ and $\mathrm{mAs}$ but different $\mathrm{mA}$ and time values. Beam alignment and Collimation. This tests check misalignment of the light field and the X-ray field. Their tolerance values are given in Table 4.

The exposure parameters which were measured are listed in Table 4, as well as their acceptability criteria [8-10]. As shown in Figure 2, the beam alignment and collimation tests were performed using the collimator test tools RMI at 1 meter from the X-ray tube focus to the test tool which was placed on the examination table, with the X-ray exposure parameters set at $60 \mathrm{kV}, 10 \mathrm{mAs}$ and 1 meter FFD. The $\mathrm{kV}$ reproducibility, $\mathrm{kV}$ accuracy, mAs Linearity tests were performed using UNFORS test device of Serial No.190017. Also alluminum sheets (No. 1100) were inserted between the tube and the detector of UNFORS test device for beam quality measurement (HVL). The radiation leakage measurements were performed using Berthold survey meter Serial No. 2460 with its probe Serial No.164610-2460 (figure 1) at 1 meter away from the tube at the exposure parameters of $90 \mathrm{kV}, 100 \mathrm{mAs}$, and 1 meter FFD.

For shielding effectiveness, the measurements of radiation levels of the premises were performed using Thermo survey meter with Model No. ESM FH 40G-L10 and Serial No. 019890, at 90 kV, $100 \mathrm{mAs}$, and 1 meter FFD. In this test, a plastic gallon filled with 5 liters of water was placed in the beam to create maximum scatter. Water was used as the studies shows that $65-70 \%$ of human body is composed of water $[14,15,16]$. The UNFORS test device of Serial No.190017 was calibrated by manufacture. The Berthold survey meter Serial No. 2460 with its probe/detector Serial No.164610-2460 and the Thermo survey meter with Model No. ESM FH 40G-L10 and Serial No. 019890 were calibrated in SSDL (Secondary Standard Dosimetry Laboratory) in Arusha Tanzania. Their calibration certificates were valid during the measurements. 
Table 2: Evaluation criteria for legal requirements

\begin{tabular}{lc}
\hline Evaluation criteria & Response \\
\hline Availability of valid License (possess and use) & Yes/No \\
\hline $\begin{array}{l}\text { The centre have been fined or/and closed for non- } \\
\text { compliance }\end{array}$ & Yes/No \\
\hline
\end{tabular}

Table 3: A checklist of Basic requirements (Design and Layout) Compliance on X-ray facility

\begin{tabular}{|c|c|c|}
\hline Measured Parameter & Acceptable criteria & Responses \\
\hline X-ray room size & $\begin{array}{l}\text { About } 16 \text { square meters }(4 \mathrm{~m} \text { by } 4 \mathrm{~m}) \\
\text { (Tolerance } \pm 5 \% \text { ) }\end{array}$ & (Pass/ Fail) \\
\hline \multirow[t]{2}{*}{ Doors and Walls } & Doors lined with lead sheet of $2 \mathrm{~mm}$ & (Pass/ Fail) \\
\hline & Wall of concrete of $30 \mathrm{~cm}$ thick & (Pass/ Fail) \\
\hline $\begin{array}{l}\text { Windows and } \\
\text { Air Conditioners }\end{array}$ & Should be $2 \mathrm{~m}$ above the floor & (Pass/ Fail) \\
\hline \multirow[t]{3}{*}{ Control Cubicles } & Within the X-ray room & (Pass/ Fail) \\
\hline & Minimum height of $2 \mathrm{~m}$ & (Pass/ Fail) \\
\hline & Protective lead glass of $2 \mathrm{~mm}$ thick & (Pass/ Fail) \\
\hline Changing Cubicle & Within the X-ray room & (Pass/ Fail) \\
\hline \multirow{2}{*}{$\begin{array}{l}\text { Radiation warning } \\
\text { notice, lights and } \\
\text { Symbols }\end{array}$} & Red warning light at the entrance & (Pass/ Fail) \\
\hline & Radiation warning symbols and notice & (Pass/ Fail) \\
\hline \multirow{2}{*}{$\begin{array}{l}\text { Dark room (if not } \\
\text { Computerized) }\end{array}$} & Air extractor & (Pass/ Fail) \\
\hline & Light tight for safety of X-ray films & (Pass/ Fail) \\
\hline \multirow[t]{2}{*}{ Other requirements } & $\begin{array}{l}\text { Protective gears, at least } 2 \text { lead apron, } 2 \text { Gonadal shield, } 2 \text { thyroid } \\
\text { shield and } 1 \text { pair of lead gloves all of } 0.5 \mathrm{~mm} \mathrm{~Pb}(<3 \text { fail, } \\
\text { otherwise pass) }\end{array}$ & (Pass/ Fail) \\
\hline & $\begin{array}{l}\text { A qualified x-ray machine operator with a minimum qualification } \\
\text { of Diploma in Diagnostic Radiology. }\end{array}$ & (Pass/ Fail) \\
\hline
\end{tabular}

Table 4: Parameters and acceptability criteria for medical X-ray units

\begin{tabular}{ll}
\hline Measured Parameter & Acceptable limits \\
\hline Beam alignment & $\leq 3 \%$ of FID \\
\hline Collimation & $\leq \pm 2 \mathrm{~cm}$ \\
\hline kV reproducibility & $\leq \pm 5 \%$. \\
\hline kV accuracy & $\pm 10 \%$ \\
\hline mAs Linearity & $\pm 10 \%$ \\
\hline Beam quality (HVL) & $\geq 2.3 \mathrm{~mm} \mathrm{Al}$ \\
\hline The tube radiation leakage & $<1000 \mu \mathrm{Gy} / \mathrm{hr}$ \\
\hline Radiation levels of the premises & $<10 \mu \mathrm{Sv} / \mathrm{hr}$ for classified workers and \\
& $<0.5 \mu \mathrm{Sv} / \mathrm{hr}$ for members of public \\
\hline
\end{tabular}


Figure 1: A picture of UNIFORS Testing device, Thermo survey meter, Berthold survey meter with its probe and a Tape measure (for length measurements)
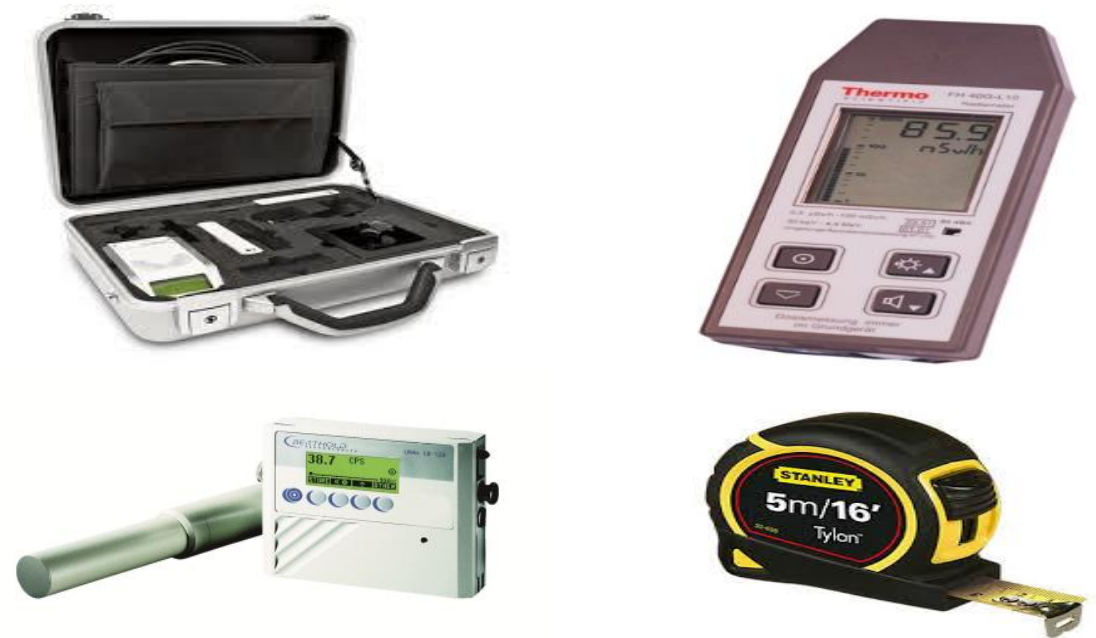

Figure 2: The Quality Control (QC) experimental setup

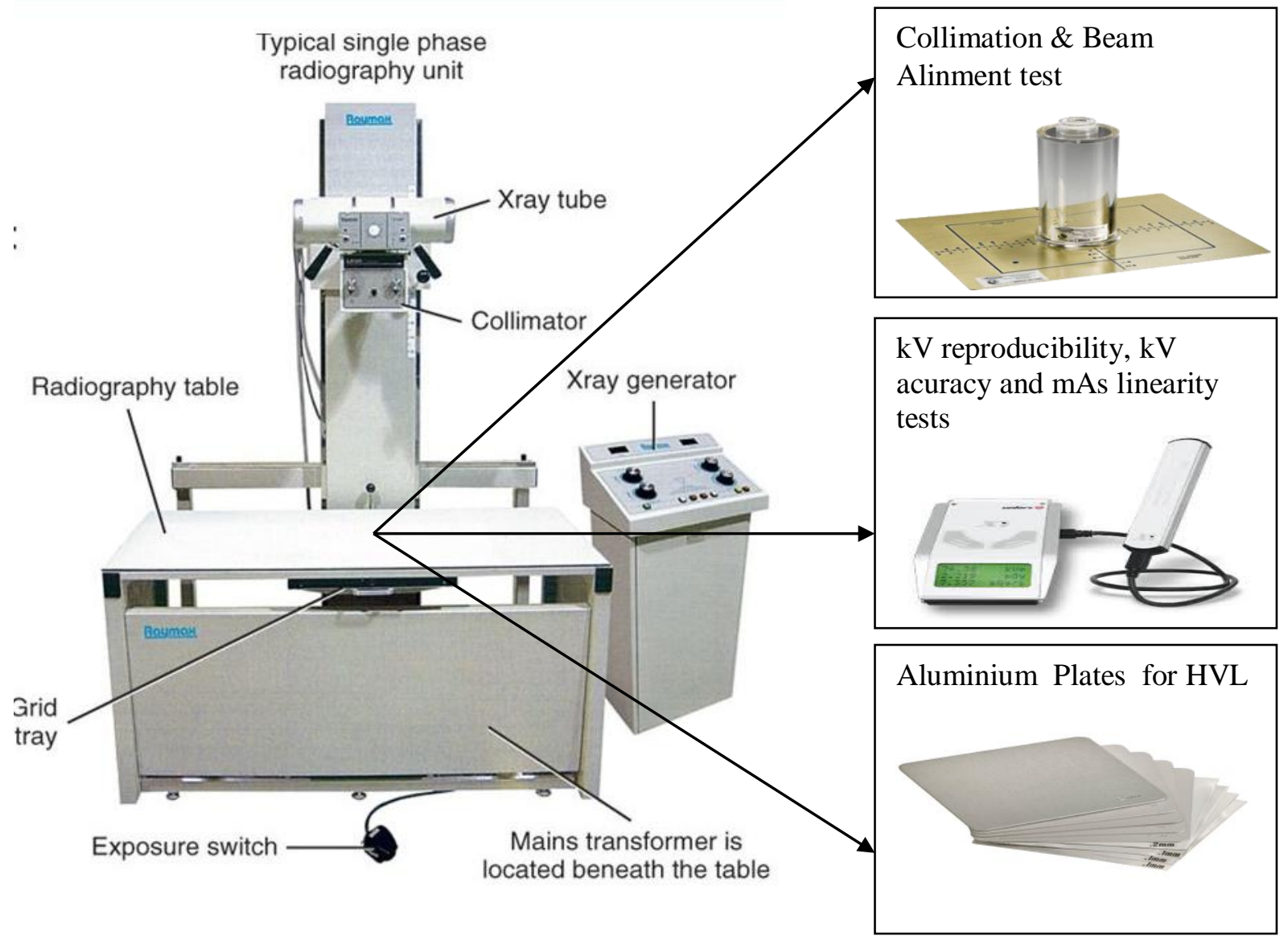




\section{RESULTS AND DISCUSSION}

\subsection{Legal and Basic (design and layout) compliance}

The regulatory bodies (e.g. TAEC) are required to issue the authorization certificate to operator after meeting all the standards and requirements [17]. The contents of the certificates are given in IAEA documents [17]. In Tanzania, the Centers are required to apply for license (possess and use) of the medical diagnostic X-ray equipment each year [5]. The licenses are valid from July of a particular year to June of the following year (e.g. July 2016 to June 2017). On the issue of license, 60 X-ray facilities were evaluated. Of the visited X-ray facilities, $9(15 \%)$ centers were new, not rendering X-ray services and do not pursue and use license and have not yet applied for it. Also 6 $(10 \%)$ of the centres were new, not rendering X-ray services but have applied for the license. In the visited centres, we found $5(8.3 \%)$ centres rendering X-ray services without a license but they have applied for it. Then $10(16.7 \%)$ centers were found operating without a license and have not applied for it, and one of them was fined and close. It therefore, implies that the owners of this Xray units has gone against the section 18 (1) of the Atomic Energy Act No. 7 of 2003. However, of the remaining, 30 (50\%) X-ray facilities had valid licenses for the particular year.

For standard compliance monitoring, the basic requirements on the design of X-ray rooms were used as assessment criteria. However, not all the requirements on each item were assessed, only the requirements considered very important by researches were included into this study. One of the criteria of was X-ray room size. $60 \mathrm{X}$-ray units were evaluated, of the assessed X-ray rooms, 54 (90 $\%) \mathrm{X}$-ray rooms were in acceptable design and size for medical X-ray examinations. Most of windows and air conditioners of the X-ray facilities were in acceptable design, of the remaining, 15 (25\%) of the X-ray facility failed on these criteria. The dark rooms were also evaluated; the assessment criteria based on the presence of air extractor and light tight condition that would not allow the distortion of X-ray films. 59 X-ray units were assessed, of the evaluated units 28 (47\%) agreed on the criteria above. However, dark room is an old technology, and therefore, 23 (39\%) of the facilities used the computerized radiograph (CR) system. The remaining 8 (14\%) failed because either they did not have air extractor or they had the problem of light leak in the dark room. 
The general observation on the quality of walls and doors of X-ray facilities was done, 60 X-ray units were evaluated base on this criteria. However, 2 units were not functioning; therefore it was not possible to test radiation leakage on the doors and walls. The design and size of the walls were in acceptable forms. Of the assessed X-ray facilities, it was found that the doors of $31(53 \%) \mathrm{X}$-ray facilities were aligned with $2 \mathrm{~mm}$ of lead or $4 \mathrm{~mm}$ of iron and all the walls were made of concrete of range from $25 \mathrm{~cm}$ to $40 \mathrm{~cm}$. This means that, they agreed well with the criteria. However, 27 (47 $\%$ ) of X-ray facility failed this criterion as they were aligned with $2 \mathrm{~mm}$ of iron and radiation leakage was noticed along the walls and doors during the testing. In detail, the results indicate that the door that leads to the X-ray room of $15 \mathrm{X}$-rays facilities were not efficiently lead lined. Also 12 X-ray facilities had radiation leakage via the viewing windows. These inadequacies have led to the high dose rate at the reception and patient waiting area, control cubicles as well as patients changing cubicles. In some X-ray facilities, the door could not close automatically during the exposure to prevent intruders. It is necessary to note that controlled access to areas where radiation exposure may be taking place is required.

Of the evaluated X-ray units, only 7 (12\%) units out of 59 did not have control cubicles. The changing cubicles were also observed as problem in almost more than half of the surveyed facilities. Out of 59 X-ray unit surveyed, 28 (47\%) of the facilities did not have the patients changing cubicles. The results also show that the control cubicles and patient changing cubicle in some X-ray facility were not of quality as they were not efficiently aligned with lead of $2 \mathrm{~mm}$ or iron of $4 \mathrm{~mm}$. Interlocks were not provided for the doors and in some hospitals the radiation levels within the cubicles were higher than $10 \mu \mathrm{Sv} / \mathrm{hr}$. It therefore, implies that the issue of dose optimization is not of concern in these X-ray facilities.

In all 59 assessed X-ray facilities, 24 (41\%) did not had enough protective gears (e.g. lead apron) while $3(5 \%)$ completely did not have any protective gear. It therefore, implies that in the X-ray units of these hospitals, the issue of safety of personnel and patients are not adequately taken into consideration. The lead aprons, Gonadal shields and other protective gears are required to be worn by the radiographers during exposure were not adequate and visibly missing in some X-ray 
facilities. Also about 27 (46 \%) out of 59 X-ray units were operated by unqualified personnel. This is against the section 19 (1) of the Atomic Energy Act No. 7 of 2003, which prohibit unqualified personnel to administer ionization radiation to patients. It is also evident that hazards warning light and radiation warning symbols were not available in $22(38 \%)$ out of 59 X-ray facilities evaluated. This trend is an indication that the principle of as low as reasonably achievable (ALARA-Principle) is not of concern not adopted or practiced in these X-ray facilities of the surveyed hospitals.

Figure 3: The assessment of Legal and Basic/ Standard requirements of the X-ray facility

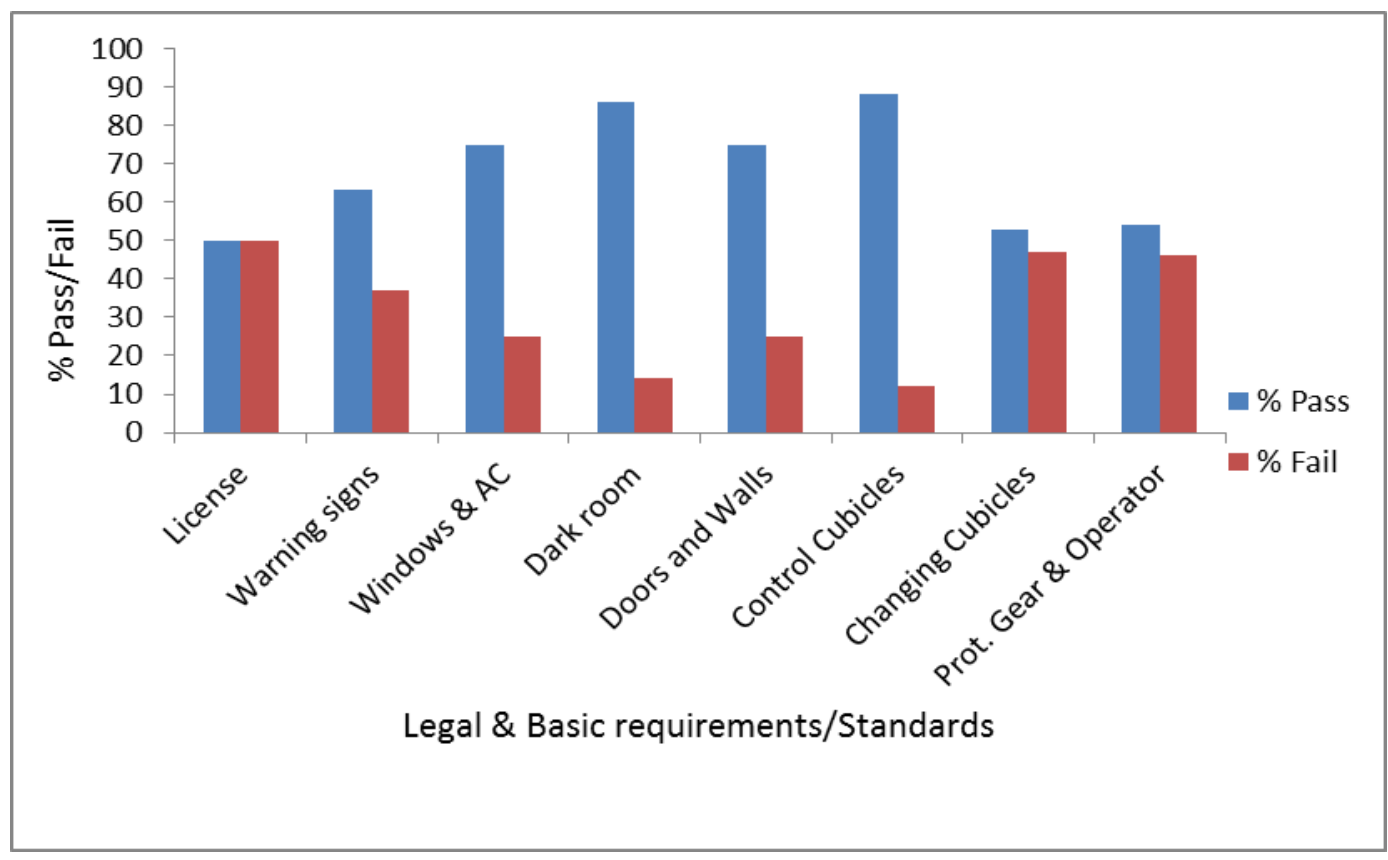

The legal and basic requirements were assessed in term of pass or fail basing on criteria given in Table 3. As shown in Figure 3, the issue of license, changing cubicles, protective gears and qualifications of operator seems to be a problem in surveyed hospitals. The other criteria did not have many problems. Only one study in Tanzania reported on dark rooms quality. The assessment was based in terms of film fog, film storage and cleanliness. The results showed that about $70 \%$ of 400 X-ray dark room facilities were adequate [18]. However, awareness on the importance of these criteria in relation to radiation protection is needed. 


\subsection{Quality Control tests}

In this paper, for the light beam and actual X-ray beam, 4 (7\%) out of $58 \mathrm{X}$-ray units showed a difference of more than $3 \%$ of FID (Focus to Image Distance). Moreover, the remaining 54 (93\%) $\mathrm{X}$-ray tubes analyzed showed that the beam was properly aligned and within the acceptable limit of $\leq 3 \%$ and radiographs shows an image shift between radiation and light beam on the $\pm \mathrm{X}$ axis and $\pm \mathrm{Y}$ axis. However, out of 58 tested X-ray units, only $2(3.4 \%)$ units had unacceptable results as the radiograph shows an image shift of more than $2 \mathrm{~cm}$ towards $-Y$ direction. This is not acceptable as it is beyond the maximum allowable limit of $\pm 2 \mathrm{~cm}$. The remained $56(96.6 \%) \mathrm{X}$-ray units had an image shift within the acceptable limits of $\pm 2 \mathrm{~cm}$.

The analysis of test results showed that $55(95 \%)$ out of 58 X-ray units had acceptable deviation between nominal and measured values of $\mathrm{X}$-ray tube voltage ( $\mathrm{kV}$ accuracy) within the tolerance limit of $\pm 10 \%$ and the HVL reported were ranged from $2.09 \mathrm{mmAl}$ to $5.86 \mathrm{mmAl}$, with a mean value of $3.54 \mathrm{mmAl} \pm 0.93 \mathrm{SD}$ at $80 \mathrm{kV}$ actual beam. These measurements on the X-ray tubes showed that 56 out of $57 \mathrm{X}$-ray units had adequate beam filtration ( $\mathrm{HVL} \geq 2.3 \mathrm{mmAl}, 80 \mathrm{kVp}$ ), whereas $57(98 \%)$ out of 58 exposures had acceptable $\mathrm{kV}$ reproducibility as the variations were within the tolerance limit of 5\%. Of the X-ray generators assessed, $53(93 \%)$ had tolerable ( $\pm 10 \%)$ mAs linearity. The remained $4(5.3 \%)$ X-ray unit failed total as the mAs linearity were higher than the acceptable limit and the other unit the mAs linearity could not be performed due to failure of lower kVs which are normally used for that test.

The test on tube leakage was performed in $14 \mathrm{X}$-ray units only. The results showed that 13 (93\%) X-ray units had tube radiation leakage of less than $1000 \mu \mathrm{Gy} / \mathrm{hr}$ at $1 \mathrm{~m}$ in any direction for true 80 $\mathrm{kV}$. This dose rate is within the acceptable limit $(<1000 \mu \mathrm{Gy} / \mathrm{hr})$. However, for the remaining 46 X-ray units this measurement was not taken. The shielding effectiveness measurements of the premises were performed. 31 (53\%) out of 58 tested premises of X-ray units had radiation levels within the acceptable limits for both classified workers and member of public. However, the remaining units had radiation levels above the acceptable limits. The most recorded areas with radiation leakage is at the main door (D1) leading to the X-ray rooms and the registration area, the 
dose rates were higher than $0.5 \mu \mathrm{Sv} / \mathrm{hr}$, and hence pose threat to the members of public. Within the $\mathrm{X}$-ray rooms, higher dose rates (>10 $\mu \mathrm{Sv} / \mathrm{hr}$ ) were recorded at viewing windows (lead glass), at the walls and doors of control cubicles and behind the doors of changing cubicles. These dose rates are above the acceptable limits for classified workers.

Figure 4: Evaluation of exposure parameter based on recommended limits

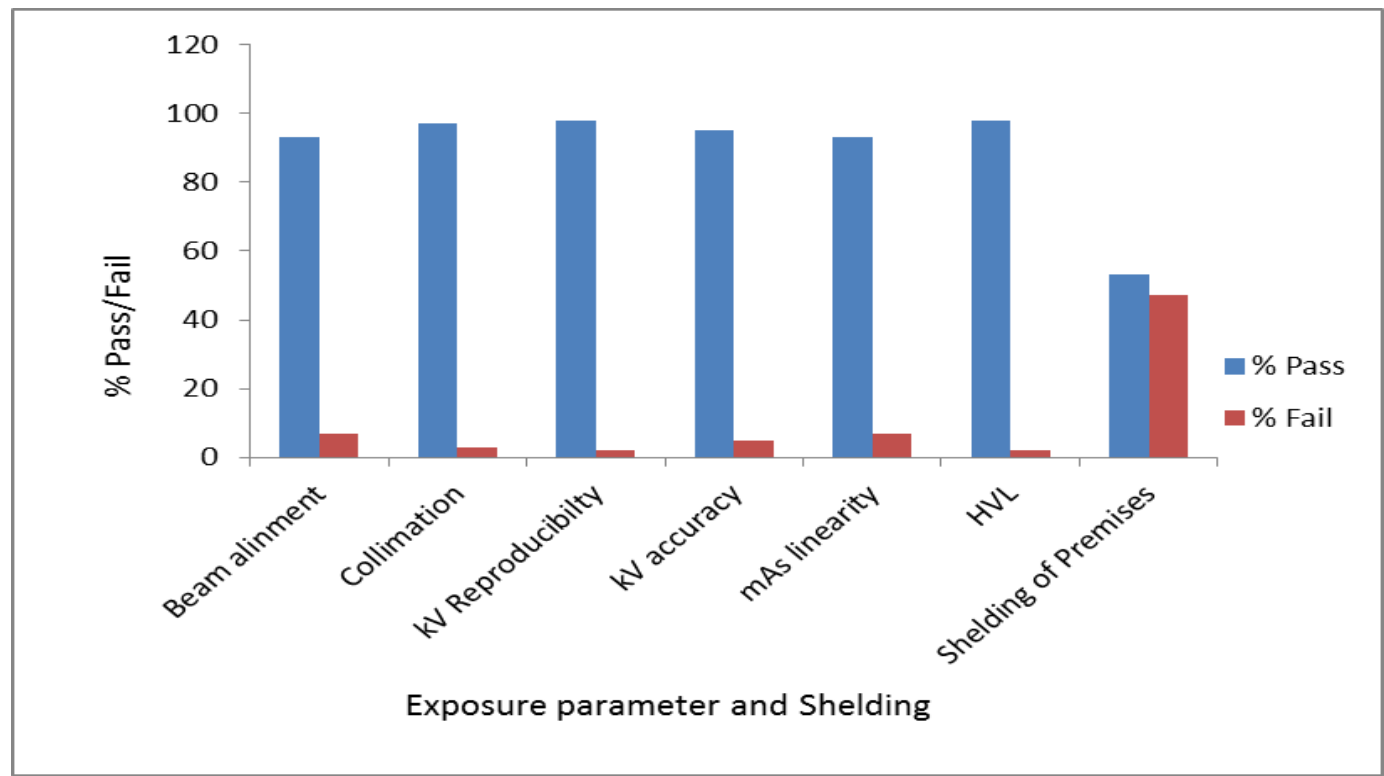

As shown in figure 4, the exposure parameter was in acceptable conditions as they were within the recommended limits. Only parameter that suffers from this study is shielding of the premises. The radiation leakage was observed $27(47 \%)$ of the assessed X-ray facilities, the problem was more observed at door (D1) leading to the X-ray rooms, in the changing and control cubicles and patients waiting areas. This was a result of poor shielding.

As shown in figure 5, without regarding the number of equipment test, the results from this study seems to be good when compared to previous results of X-ray units evaluated in Tanzania. The results shows that, for beam alignment test $69 \%, 86 \%$ and $60 \%$ in 22, 400 and 80 units tested pass the test [18-20]. In the area of beam collimation the same trend was observed. For kV (accuracy and reproducibility) tests, $50 \%$ and $88 \%$ in 16 and 400 units tested were declared as pass [ 18, 19], whilst $59 \%$ and $41 \%$ in 120 units test were declared as pass [20]. All the tested 400 units had 
acceptable results of HVL ( $\geq 2.3 \mathrm{~mm} \mathrm{Al}$ ) [18]. Radiation leakage test shows that, $100 \%$ and $19.9 \%$ in 2 and 47 units test passed the test. In the reviewed literature in this study, in Tanzania, out of 57 X-ray unit tested, $36.8 \%$ did not qualify and the reason for this failure was the age of the equipment. Most of the equipment were more than 15 years old [19]. Also the issue of age of equipment was also a problem in Serbia and in Thailand as well [1, 21].

Figure 5: Comparison of \% Pass in QC tests in Tanzania

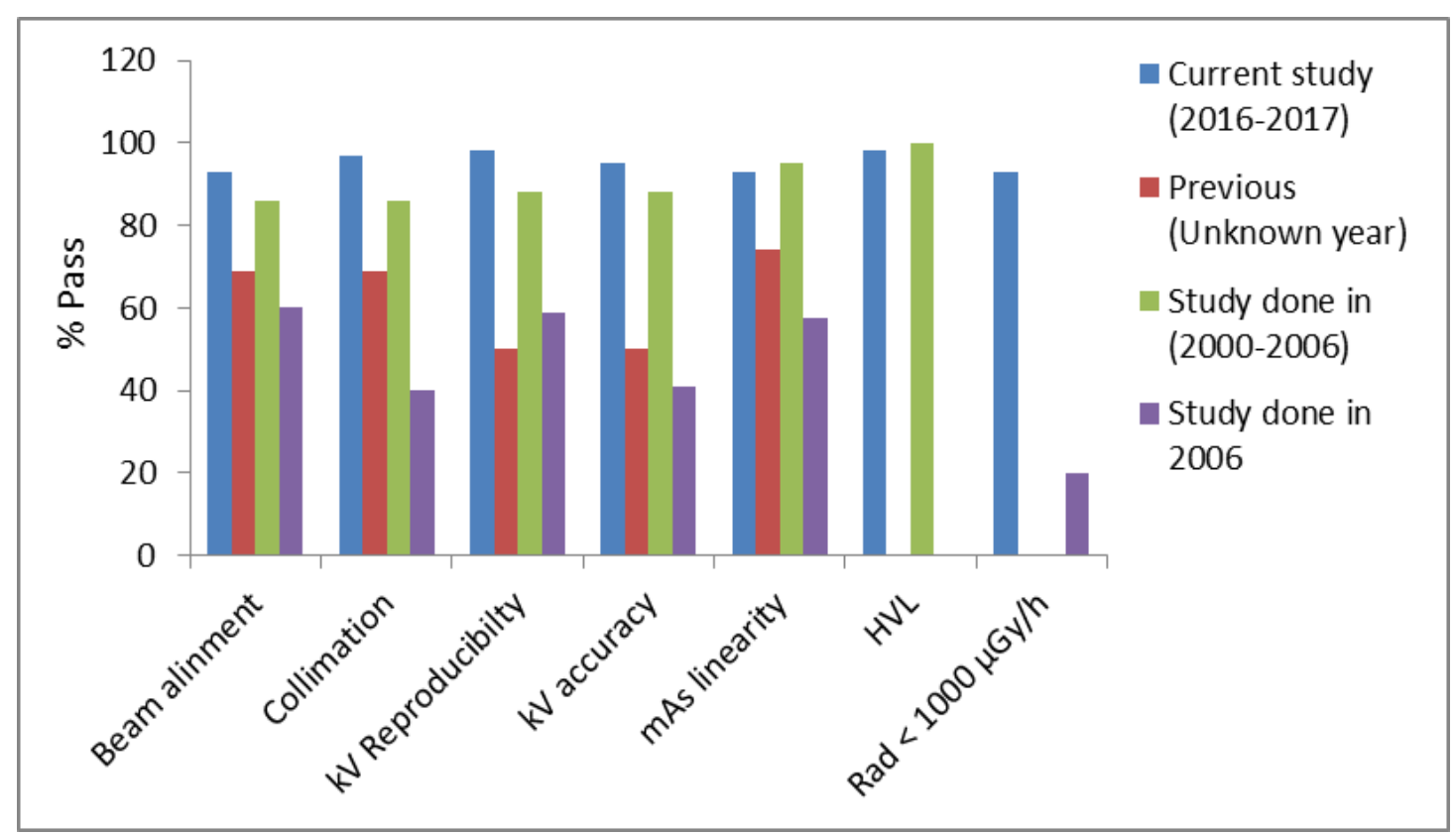

The good performance of most X-ray units evaluated in this study were largely attributed to installation of new X-ray machines in both public and private health facilities, this project started in 2006. In view of the above, it is evident that studies done from 2006 shows that most X-ray machines were within the recommended tolerance limits and hence optimum equipment performance. The results shows that the radiation protection of workers and patients has improved compared to previous years. The reasons for the improvement are enactment of the atomic energy act of 2003 and its regulations increased the number of compliances, also the installation of new Xray machine in hospitals (especial government hospitals) through a joint project between the governments of Tanzania and the Netherlands [18] 


\section{CONCLUSION}

The results presented here confirm that the test results of quality control in diagnostic X-ray equipment were within the acceptable limits. The problem was observed on the effectiveness of shielding where the dose rate higher than $0.5 \mu \mathrm{Sv} / \mathrm{hr}$ and $10 \mu \mathrm{Sv} / \mathrm{hr}$ were observed in different areas of the X-ray facilities. A major problem was observed on the basic requirements of the X-ray design, the patients changing cubicles and radiation warning signs were not available in some facilities. In some X-ray facilities, the protective gears were not adequate or not available while others were operated by unqualified personnel. This trend is an indication that the principle of as low as reasonably achievable (ALARA) principle was not adopted in X-ray facilities. The study recommends that for non-compliance, TAEC as a regulatory body needs to enforce the law by executing its power, also the hospitals needs to purchase brand new X-ray machines as the used (old ones) are reported to have some problems in $\mathrm{kV}$ setup.

\section{REFERENCES}

1. PLAINOI P, DISWATH W AND MANATRAKUL N. Quality control and Patient Doses from X-ray examinations in some Hospitals in Thailand; Ministry of Public Health, Nonthaburi, Thailand. IAEA-CN-85-288. XA0101612; 1998 - 2000.

2. IAEA-International Atomic Energy Agency. Basic Safety Standards for Protection against Ionizing Radiation and for the Safety of Radiation Sources, Safety Series No. 115, IAEA, Vienna (1996).

3. KORIR, G.K, WAMBANI, J.S, KORIR, I.K. Establishing a quality assurance baseline for radiological protection of patients undergoing diagnostic radiology. S.A Jour of Radiology. Vol. 15 (3), p. 70-79, 2011.

4. OLUWAFISOYE PA, OLOWOOKERE CJ, JIBIRI NN, BELLO TO, ALAUSA SK AND EFUNWOLE HO. Quality control and environmental assessment of equipment used in diagnostic radiology. Int. J. of Res and Rev in Applied Sci. Vol. 3 (2), p. 148-58, 2010. 
5. United Republic of Tanzania. Atomic Energy Act No.7 of 2003, Government Publications Dar es salaam, Tanzania, 2003.

6. URT-United Republic of Tanzania. National Inventory of People administering ionization radiation: Ministry of Health and Social Welfare. 2017.

7. IAEA-International Atomic Energy Agency. Organization and Implementation of a National Regulatory Infrastructure Governing Protection against Ionizing Radiation and the Safety of Radiation Sources, IAEA-TECDOC-1067, IAEA, Vienna, 1999.

8. Title 21, Code of federal Regulations, Part 800-1299, FDA, U.S. Government Printing Office, Washington DC. 1991 and revisions.

9. National Council on Radiation Protection and Measurement: Quality Assurance for Diagnostics Imaging Equipment. NCRP 99, NCRP, Bethesda, Maryland. 1988.

10. AAPM-American Association of Physicists in Medicine, report No. 31, Standardized Methods for Measuring Diagnostic X-ray Exposure, AAPM Diagnostic X ray Imaging Committee TG No. 8; 1991

11. URT-United Republic of Tanzania. National Inventory of Radiation Emitting Devices. 2016.

12. URT-United Republic of Tanzania. Population Distribution by Administrative Units. 2013.

13. MUNRO, LEONIE. Basics of Radiation Protection, how to achieve ALARA: Working tips and guidelines. World Health Organisation (WHO), Geneva, 2004.

14. LARRY, A.D, AND MICHEL, K. The Phantoms of Medical and Health Physics: Device for Research and development. Springer Science and Business Media, 2013.

15. YOHANNES I, KOLDITZ D, LANGNER O, AND KALENDER W.A. A formulation of tissue-and water equivalent materials using the stoichiometric analysis method for CT number calibration in radiotherapy treatment planning. Physics in Medicine and Biology. Vol. 57, p. 1173 - 1190, 2012.

16. Water and Our Health (Drops of water 3). Available at: < http://www.unesco.org/fileadmin/MULTIMEDIA/FIELD/Venice/pdf/special events/bozza scheda_DOW03_1.0.pdf $>$. Last accessed: 17/3/2017. 
17. IAEA-International Atomic Energy Agency. Notification and Authorization for the safe use of Radiation sources, IAEA-TEC-DOC 1525, Vienna, 2007.

18. MWALONGO D. A, NGAILE J. E, SUNGITA Y.Y. Performance evaluation of conversional X-ray machines in Tanzania. Conference Paper • October. 2008

19. SUNGITA Y.Y, MDOE S.L, NGATUNGA J, KITOSI A.E AND MUHOGORA W.E. Quality Assurance for Diagnostic X-ray Machines in Tanzania. IAEA-CN-70/6. XA9848213.

20. SUNGITA Y.Y, MDOE S.L, MSAKI, P. Diagnostic X-ray Facilities as per quality control performances in Tanzania. Journal of Applied Clinical Medical Physics, Vol. 7(4), 2006. Page 66-73.

21. CIRAJ, O, KOŠUTIĆ, D, AND MARKOVIĆ, S. Quality control of conventional diagnostic Radiology equipment in Serbia and Montenegro: VINČA Institute of Nuclear Sciences, Belgrade, Serbia and Montenegro: 2003. 